\title{
Exchange Rates and Fundamentals: Evidence on the Economic Value of Predictability ${ }^{* \dagger}$
}

\author{
Abhay Abhyankar ${ }^{a}$, Lucio Sarno ${ }^{b, c}$ and Giorgio Valente ${ }^{b}$ \\ a: University of Durham \\ b: University of Warwick \\ c: Centre for Economic Policy Research (CEPR)
}

First version: September 2003 - Second revised version: September 2004

\begin{abstract}
A major puzzle in international finance is the well-documented inability of models based on monetary fundamentals to produce better out-of-sample forecasts of the nominal exchange rate than a naive random walk. While this literature has generally employed statistical measures of forecast accuracy, we investigate whether there is any economic value to the predictive power of monetary fundamentals for the exchange rate. We find that, in the context of a simple asset allocation problem, the economic value of exchange rate forecasts from a fundamentals model can be greater than the economic value of random walk forecasts across a range of horizons.
\end{abstract}

JEL classification: F31; F37.

Keywords: foreign exchange; monetary fundamentals; predictability; forecast evaluation; asset allocation.

*Acknowledgments: This paper was partly written while Lucio Sarno was a Visiting Scholar at the Federal Reserve Bank of St. Louis, the International Monetary Fund and the Central Bank of Norway. The research reported in this paper was conducted with the aid of a research grant from the Economic and Social Research Council (ESRC Grant No. RES-000-22-0404). The authors are grateful for useful conversations or constructive comments on earlier drafts to Charles Engel (editor), two anonymous referees, Karim Abadir, Badi Baltagi, Jerry Coakley, John Driffill, Bob Flood, Philip Franses, Petra Geraats, Peter Ireland, Peter Kenen, Rich Lyons, Michael McCracken, Chris Neely, David Peel, Alan Stockman, Mark Taylor, Dick van Dijk, Bob Webb, Ken West and to participants in seminars at Boston College; University of Virginia; University of Oxford; University of Texas A\&M; International Monetary Fund; Inter-American Development Bank; Birkbeck College; University of Essex; University of Leicester; University of Exeter; Central Bank of Norway; Econometrics Institute of the Erasmus University, Rotterdam; LUISS University, Rome; University of Tor Vergata, Rome; Renmin University, Beijing; the 2002 Macro Money and Finance Annual Conference at the University of Warwick. The authors alone are responsible for the views expressed and any errors that may remain.

${ }^{\dagger}$ Corresponding author: Lucio Sarno, Finance Group, Warwick Business School, University of Warwick, Coventry CV4 7AL, UK. Tel: +44-2476-528219. Fax: +44-2476-572871. E-mail: lucio.sarno@warwick.ac.uk. Addresses for other authors: Abhay Abhyankar, Durham Business School, University of Durham, Mill Hill Lane, Durham City DH1 3LB, UK. Giorgio Valente, Finance Group, Warwick Business School, University of Warwick, Coventry CV4 7AL, UK. 


\section{Introduction}

In a highly influential paper, Meese and Rogoff (1983) noted that the out-of-sample forecasts of exchange rates produced by structural models based on fundamentals are no better than those obtained using a naive random walk or no-change model of the nominal exchange rate. These results, seen as devastating at the time, spurred a large literature that has re-examined the robustness of the Meese-Rogoff results, which represent an element of the 'exchange rate disconnect puzzle' (Obstfeld and Rogoff, 2000). Some recent research, using techniques that account for several cumbersome econometric problems, including small sample bias and near-integrated regressors in the predictive regressions, suggests that models based on monetary fundamentals can explain a small amount of the variation in exchange rates (e.g., Mark, 1995; Mark and Sul, 2001). However, others remain skeptical (e.g., Berkowitz and Giorgianni, 2001; Faust, Rogers and Wright, 2003). Thus, even with the benefit of almost twenty years of hindsight, the Meese-Rogoff results have not been convincingly overturned: evidence that exchange rate forecasts obtained using fundamentals models are better than forecasts from a naive random walk is still elusive (e.g., Neely and Sarno, 2002; Cheung, Chinn and Pascual, 2003).

Prior research on the ability of monetary-fundamentals models to forecast exchange rates relies on statistical measures of forecast accuracy, like root mean squared errors. Surprisingly little attention has been directed, however, to assessing whether there is any economic value to exchange rate predictability (i.e., to using a model where the exchange rate is forecast using economic fundamentals). The present paper fills this gap. We investigate the ability of a monetary-fundamentals model to predict exchange rates by measuring the economic or utility-based value to an investor who relies on this model to allocate her wealth between two assets that are identical in all respects except the currency of denomination. We focus on two key questions. First, as a preliminary to the forecasting exercise, we ask how exchange rate predictability affects optimal portfolio choice for investors with a range of horizons up to ten years. Second, and more importantly, we ask whether there is any additional economic value to a utilitymaximizing investor who uses exchange rate forecasts from a monetary-fundamentals model relative to an investor who uses forecasts from a naive random walk model. We quantify the economic value of predictability in a Bayesian framework that allows us to account for uncertainty surrounding parameter estimates in the forecasting model. Indeed, parameter uncertainty or 'estimation risk' is likely to be of importance, especially over long horizons.

Our results with regard to the two questions addressed in this paper, obtained using three major US dollar exchange rates during the recent float and considering forecast horizons from 1 to 10 years, are as 
follows. First, we find that exchange rate predictability substantially affects, both quantitatively and qualitatively, the choice between domestic and foreign assets for all currencies and across different levels of risk aversion. Specifically, exchange rate predictability can generate optimal weights to the foreign asset that are substantially different (in magnitude and, sometimes, in sign) from the optimal weights generated under a random walk model. ${ }^{1}$ Second, our main result is that we find evidence of economic value to exchange rate predictability across all exchange rates examined and for a wide range of plausible levels of risk aversion. In particular, the realized end-of-period wealth achieved by a US investor over a ten-year horizon using a monetary fundamentals-exchange rate model for forecasting the exchange rate is higher than the corresponding end-of-period wealth obtained by an investor who acts as if the exchange rate were a random walk. Our results show that the economic value of predictability can be substantial also over relatively short horizons and across different levels of risk aversion. We view our findings as suggesting that the case against the predictive power of monetary fundamentals may be overstated.

An important related paper is the study of West, Edison and Cho (1993), who also focus on a utilitybased metric of forecast evaluation rather than conventional statistical criteria. Our paper differs from their work in several respects. First, their focus is on exchange rate volatility, whereas our focus is on the level of the exchange rate in the tradition of the literature inspired by Meese and Rogoff (1983). Specifically, West, Edison and Cho examine various time series models for the conditional variance of the exchange rate change. Second, we analyze the relationship between exchange rates and macroeconomic fundamentals (money and income) implied by exchange rate determination theory, whereas they use weekly dollar exchange rates and the corresponding pairs of Eurodeposit rates. Third, while West, Edison and Cho carry out their asset allocation analysis in the context of a static mean-variance setting, our framework builds on their work to analyze a more general setting, allowing for parameter uncertainty, a different utility function and also, in the more complex case examined, for dynamic, multi-period asset allocation over long investment horizons.

Our work builds on earlier research by Kandel and Stambaugh (1996) and Barberis (2000), who use a Bayesian framework to study asset allocation ${ }^{2}$ between a riskless asset and risky equities. Our work differs from theirs in three important ways. First, since we consider the economic gains (losses) to

\footnotetext{
${ }^{1}$ Further, we find that taking into account parameter uncertainty causes the allocation to the foreign asset to fall (in absolute value) relative to the case when parameter uncertainty is not taken into account, effectively making the foreign asset look riskier. We do not report below our results relating to the case where parameter uncertainty is not taken into account, but these results are given in the working paper version (Abhyankar, Sarno and Valente, 2004).

2 This decision-theoretic approach has also been used recently by Baks, Metrick and Wachter (2001), Bauer (2001), Shanken and Tamayo (2001), Xia (2001), Avramov (2002), Cremers (2002) and Paye (2004). See also Karolyi and Stulz
} 
an investor whose problem is allocating her wealth between two assets that are identical in all respects except the currency of denomination, our focus is on exchange rate prediction. Put differently, in our framework risk only enters the investor's problem through the nominal exchange rate. Second, we allow the investor to hold short positions in the assets, which is an important feature in real-world foreign exchange markets (e.g., Lyons, 2001). Third, while we analyze the impact of predictability on optimal allocation decisions, our primary goal is to evaluate the out-of-sample economic value of exchange rate predictability. We do this by comparing the end-of-period wealth, end-of-period utility and certainty equivalent return obtained using a standard monetary fundamentals model of the exchange rate with the corresponding measures of economic value obtained using a naive random walk, which remains the standard benchmark in the exchange rate forecasting literature.

Another related paper is Campbell, Viceira and White (2003), who study long-horizon currency allocation using a vector autoregressive framework where the predictive variables are the real interest rate and the real exchange rate. Our study differs from theirs in at least two ways. First, our basic forecasting instrument is the conventional set of monetary fundamentals proposed by exchange rate determination theory and used in the exchange rate forecasting literature since the Meese-Rogoff study. Second, our framework allows for parameter uncertainty, which may be relevant over long investment horizons.

We wish to note that, although we focus on a measure of economic value based on utility calculations, when one decides to move away from statistical criteria of forecast accuracy evaluation, there are many different ways to characterize or define economic value, and our definition, given below in Sections 4 and 6, is just one of them (e.g. see Leitch and Tanner, 1991). In this respect, we do not claim to provide a full answer to the crucial economic question of whether exchange rates are related to macroeconomic fundamentals. We do claim, however, that the use of different metrics of evaluation based on utility calculations, such as the one presented in this paper, provides an alternative way to analyze the relationship between exchange rates and fundamentals that may shed light on aspects of such relationship (or lack of it) which cannot be captured by standard statistical criteria. Another way to view our paper is as an interesting finance exercise, although there are shortcomings in our approach that the reader should bear in mind. In particular, we do not take into account transactions costs (such as bid-ask spreads), although the simple buy-and-hold strategy at the core of this paper-which requires only two transactions, at the beginning and end of the investment horizon respectively-is unlikely to be drastically affected by the allowance for transactions costs. We also ignore issues such as settlement timing and the fact that

(2003) for an elegant survey of asset allocation in an international context. 
data for macroeconomic fundamentals used in econometrics exercises of this kind may not be available at the time asset allocation decisions are made or may suffer from measurement errors.

The rest of the paper is organized as follows. Section 2 provides a brief outline of the theoretical background, while in Section 3 we describe the framework used to analyze the economic value of exchange rate predictability under parameter uncertainty. Next, in Section 4 , we describe our data set and perform a standard out-of-sample forecasting exercise using methods similar to the ones used in the relevant literature. In Section 5 we discuss our empirical results relating to the asset allocation choice of our investor over various horizons. In Section 6 we report the results from an out-of-sample forecasting exercise based on economic value calculations, for an investor who relies on the monetary fundamentals model and one who uses a random walk model in making asset allocation decisions. Section 7 provides a discussion of possible extensions of our research and reports some robustness checks. Section 8 concludes. Details of the estimation procedure and the numerical methods used are provided in a Technical Appendix.

\section{Exchange Rates and Monetary Fundamentals}

A large literature in international finance has investigated the relationship between the nominal exchange rate and monetary fundamentals. This research focuses on the deviation, say $u$, of the nominal exchange rate from its fundamental value:

$$
u_{t}=s_{t}-f_{t},
$$

where $s$ denotes the log-level of the nominal bilateral exchange rate (the domestic price of the foreign currency); $f$ is the long-run equilibrium of the nominal exchange rate determined by the monetary fundamentals; and $t$ is a time subscript.

The fundamentals term is, most commonly, given by

$$
f_{t}=\left(m_{t}-m_{t}^{*}\right)-\phi\left(y_{t}-y_{t}^{*}\right),
$$

where $m$ and $y$ denote the log-levels of the money supply and income respectively; $\phi$ is a constant; and asterisks denote foreign variables. Here $f$ may be thought of 'as a generic representation of the longrun equilibrium exchange rate implied by modern theories of exchange rate determination' (Mark and Sul, 2001, p. 32). For example, equation (2) is implied by the monetary approach to exchange rate determination (Frenkel, 1976; Mussa, 1976, 1979; Frenkel and Johnson, 1978) as well as by Lucas' (1982) equilibrium model and by several 'new open economy macroeconomics' (NOEM) models (see Obstfeld and Rogoff, 1995, 2000; and the references in the surveys of Lane, 2001, and Sarno, 2001). Hence, the link between monetary fundamentals and the nominal exchange rate is consistent with both traditional models 
of exchange rate determination based on aggregate functions as well as with more recent microfounded open economy models.

While it has been difficult to establish the empirical significance of the link between monetary fundamentals and the exchange rate due to a number of cumbersome econometric problems (e.g. Mark, 1995; Kilian, 1999; Berkowitz and Giorgianni, 2001), some recent research suggests that the monetary fundamentals described by equation (2) co-move in the long run with the nominal exchange rate and therefore determine its equilibrium level (Groen, 2000; Mark and Sul, 2001; Rapach and Wohar, 2002). This result implies that current deviations of the exchange rate from the equilibrium level determined by the monetary fundamentals induce future changes in the nominal exchange rate which tend to correct the deviations from long-run equilibrium, so that estimation of a regression of the form

$$
\Delta_{k} s_{t+k}=\alpha+\beta_{k} u_{t}+\varepsilon_{t+k}
$$

(where $\Delta_{k}$ denotes the $k$-difference operator) often produces statistically significant estimates of $\beta_{k}$ (e.g., Mark, 1995; Mark and Sul, 2001). Indeed, equation (3) is the equation analyzed by a vast literature investigating the ability of monetary fundamentals to forecast the nominal exchange rate out of sample at least since Mark (1995). ${ }^{3}$ In this paper, we follow this literature and use equation (3) in our empirical analysis, imposing the conventional restriction that $\phi=1$ in the definition of $f_{t}$ given by equation (2) (e.g., Mark, 1995; Mark and Sul, 2001).

\section{International Asset Allocation, Predictability and Parameter Uncertainty: Methodology}

In this section we describe our framework for measuring the economic value of predictability of exchange rates under parameter uncertainty. Our work is related to and builds on the empirical finance literature that analyzes asset allocation in a Bayesian framework, including the work of Kandel and Stambaugh (1996) and Barberis (2000). ${ }^{4}$ We consider a utility-maximizing US investor who faces the problem of choosing how to invest in two assets that are identical in all respects except the currency of denomination. As a result we can focus on evaluating the economic and utility gains to an investor who relies on the

\footnotetext{
${ }^{3}$ Note that equation (3) implicitly assumes that deviations from long-run equilibrium are restored via movements in the exchange rate; however, it seems possible that they may be restored also via movements in the fundamentals (e.g. see Engel and West, 2002; Sarno, Valente and Wohar, 2004).

${ }^{4}$ Lewis (1989) is an example of an early application of Bayesian techniques to the foreign exchange market. See also Lewis (1995).
} 
monetary-fundamentals model to forecast exchange rates. Our benchmark is an investor who does not believe in predictability or, in other words, believes that the exchange rate follows a random walk. In our framework, the investor uses the forecasts from the model (either the fundamentals model or the random walk model) to construct strategies designed to decide how much of her wealth to invest in the domestic and foreign assets respectively.

Consider the basic problem of an investor who has to decide at time $T$ how much of her wealth to invest in nominally safe domestic and foreign bonds respectively. These two bonds yield the continuously compounded returns $r$ and $r^{*}$ respectively, each expressed in local currency. The investor wishes to hold the portfolio for $\widetilde{T}$ periods.

In our empirical work, the setup is indeed very simple. Specifically, in the case of no predictability of the exchange rate, $\Delta s_{t}$ equals a drift term plus a random error term, i.e. $\Delta s_{t}=c+$ error. In the case of predictability, we estimate a vector autoregression (VAR) assuming a monetary fundamentals equation of the form (3) as the predictive regression and a first-order autoregressive or $\mathrm{AR}(1)$ process for the deviations from the fundamentals, $u_{t}$. More formally, the predictability model is of the form:

$$
\begin{aligned}
\Delta s_{t} & =a_{1}+b_{1} u_{t-1}+\eta_{1 t+1} \\
u_{t} & =a_{2}+b_{2} u_{t-1}+\eta_{2 t+1}
\end{aligned}
$$

which is typical in this literature. ${ }^{5}$

Given initial wealth $W_{T}=1$ and defining $\omega$ the allocation to the foreign bond, the end-of-horizon or end-of-period wealth is

$$
W_{T+\widetilde{T}}=(1-\omega) \exp (r \widetilde{T})+\omega \exp \left(r^{*} \widetilde{T}+\Delta_{\widetilde{T}} s_{T+\widetilde{T}}\right)
$$

\footnotetext{
${ }^{5}$ In a more general formulation, the predictability exchange rate VAR may be written as: $z_{t}=a+B x_{t-1}+\eta_{t}$, where $z_{t}^{\prime}=\left(\Delta s_{t}, x_{t}^{\prime}\right), x_{t}=\left(x_{1, t}, x_{2, t}, \ldots, x_{n, t}\right)^{\prime}$, and $\eta_{t} \sim$ iid $(0, \Sigma)$-e.g. see Campbell (1991), Bekaert and Hodrick (1992), Hodrick (1992), Barberis (2000). The first component of $z_{t}$, namely $\Delta s_{t}$, is the change in the nominal exchange rate between period $t$ and $t-1$. The remaining components of $z_{t}$ consist of variables useful for predicting the change in the exchange rate. Thus, the VAR comprises a first equation which specifies the exchange rate change as a function of the predictor variables, while the other equations govern the stochastic evolution of the predictor or state variables. Our empirical model in equation (4) is a special case of this general formulation where $z_{t}^{\prime}=\left(\Delta s_{t}, u_{t}\right)$; $a$ is a $2 \times 1$ vector of intercept terms; $B$ is a $2 \times 1$ vector of parameters; the predictor variables vector comprises only one variable, namely the deviation from the exchange rate equilibrium level, i.e., $x_{t}=u_{t}$; and $\eta_{t}^{\prime}=\left(\eta_{1 t}, \eta_{2 t}\right)$ where $\eta_{j t}$ is the error term of the $j$ th equation in the VAR, for $j=1,2$.
} 
The investor's preferences over end-of-period wealth are governed by a constant relative risk-aversion (CRRA) power utility function of the form

$$
v(W)=\frac{W^{1-A}}{1-A},
$$

where $A$ is the coefficient of risk aversion.

The investor's optimization problem may then be written as follows:

$$
\max _{\omega} E_{T}\left\{\frac{\left[(1-\omega) \exp (r \widetilde{T})+\omega \exp \left(r^{*} \widetilde{T}+\Delta_{\widetilde{T}} s_{T+\widetilde{T}}\right)\right]^{1-A}}{1-A}\right\},
$$

where the expectation operator $E_{T}(\cdot)$ reflects the fact that the investor calculates the expectation conditional on her information set at time $T$. A key issue in solving this problem relates to the distribution the investor uses in calculating this expectation, which depends upon whether the exchange rate is predictable.

To shed light on the impact of the predictability of exchange rates on portfolio decisions, we compare the allocation of an investor who ignores predictability to the allocation of an investor who takes it into account. This can easily be done by estimating the VAR model (4), with and without the deviations from fundamentals $u_{t}$, to obtain estimates of the parameters vector, say $\theta$. $\theta$ comprises $a_{1}, a_{2}, b_{1}, b_{2}$, and the variance-covariance matrix of the error terms, say $\Sigma$. The model can be iterated forward with the parameters fixed at their estimated values, giving a distribution of future exchange rates conditional on the estimated parameters vector, $p\left(\Delta_{\widetilde{T}} s_{T+\widetilde{T}} \mid \widehat{\theta}, z\right)$, where $z_{t}=\left(z_{1}, z_{2}, \ldots, z_{T}\right)^{\prime}$ is the observed data up to the date when the investment begins. Thus, the investor's problem is

$$
\max _{\omega} \int v\left(W_{T+\widetilde{T}}\right) p\left(\Delta_{\widetilde{T}} s_{T+\widetilde{T}} \mid \widehat{\theta}, z\right) d \Delta_{\widetilde{T}} s_{T+\widetilde{T}}
$$

In order to take into account parameter uncertainty, however, one can use the posterior distribution $p(\theta \mid z)$, which summarizes the uncertainty about the parameters, given the data observed so far. Integrating over the posterior distribution, we obtain the predictive distribution of exchange rate movements conditioned only on the data observed, not on the estimated parameters vector, $\widehat{\theta}$. Then the predictive distribution is

$$
p\left(\Delta_{\widetilde{T}} s_{T+\widetilde{T}} \mid z\right)=\int p\left(\Delta_{\widetilde{T}} s_{T+\widetilde{T}} \mid \theta, z\right) p(\theta \mid z) d \theta
$$


which implies that the investor's problem under parameter uncertainty is

$$
\begin{aligned}
& \max _{\omega} \int v\left(W_{T+\widetilde{T}}\right) p\left(\Delta_{\widetilde{T}} s_{T+\widetilde{T}} \mid z\right) d \Delta_{\widetilde{T}} s_{T+\widetilde{T}} \\
= & \max _{\omega} \int v\left(W_{T+\widetilde{T}}\right) p\left(\Delta_{\widetilde{T}} s_{T+\widetilde{T}}, \theta \mid z\right) d \Delta_{\widetilde{T}} s_{T+\widetilde{T}} d \theta \\
= & \max _{\omega} \int v\left(W_{T+\widetilde{T}}\right) p\left(\Delta_{\widetilde{T}} s_{T+\widetilde{T}} \mid \theta, z\right) p(\theta \mid z) d \Delta_{\widetilde{T}} s_{T+\widetilde{T}} d \theta .
\end{aligned}
$$

Finally, given the optimal weights derived by the maximization problems (8) and (10), we can calculate the realized end-of-period wealth using the wealth function (5) for an investor who ignores parameter uncertainty-equation (8)-and an investor who recognizes it and takes it into account-equation (10). Given end-of-period wealth, we can then calculate also end-of-period utility of wealth using equation (6) and the certainty equivalent return ${ }^{6}$ to measure the economic value of predictability, as described in Section 6 below.

The maximization problems (8) and (10) are solved by calculating the integrals in these equations for values of $\omega=-100,-99, \ldots, 199,200$ (in percentage terms), which essentially allows for short selling. ${ }^{7}$ In our empirical analysis below, we report the value of $\omega$ that maximizes expected utility. The integrals are calculated by numerical methods, using 1,000,000 simulations in each experiment. In our case, the conditional distribution $p\left(\Delta_{\widetilde{T}} s_{T+\widetilde{T}} \mid \widehat{\theta}, z\right)$ is normal, so that the integral in (8) is approximated by generating 1,000, 000 independent draws from this normal distribution and averaging $v\left(W_{T+\widetilde{T}}\right)$ over all draws. For the maximization problem under parameter uncertainty, it is convenient to evaluate it in its reparameterized form (11) by sampling from the joint distribution $p\left(\Delta_{\widetilde{T}} s_{T+\widetilde{T}}, \theta \mid z\right)$-i.e., by first sampling from the posterior $p(\theta \mid z)$ and then from the conditional distribution $p\left(\Delta_{\widetilde{T}} s_{T+\widetilde{T}} \mid \theta, z\right)$-and averaging $v\left(W_{T+\widetilde{T}}\right)$ over all draws (see Appendix A for further technical details).

\section{Data and Evidence on the Exchange Rate Disconnect Puzzle}

Our data set comprises monthly observations on money supply and income (industrial production) for the US, Canada, Japan and the UK, and spot exchange rates for the Canadian dollar, Japanese yen and

\footnotetext{
${ }^{6}$ The certainty equivalent return $(\mathrm{CER})$ can be defined as the return that, if earned with certainty, would provide the investor with the utility equal to the end-of-period utility calculated for a given allocation, $\bar{v}_{T+\widetilde{T}}$. In general, the CER can be obtained by solving the equation: $v\left[W_{T}(1+C E R)\right]=\bar{v}_{T+\widetilde{T}}$, where $W_{T}$ denotes wealth at time $T$ and $v[\cdot]$ is the utility function in (6).

${ }^{7}$ Obviously no allowance for short selling would involve a weight $\omega$ between 0 and 100 . Given the wide use of short selling in the foreign exchange market, we allow $\omega$ to be defined between -100 and 200 , which essentially allows for full proceeds of short sales and assumes no transactions costs.
} 
UK sterling vis-à-vis the US dollar. The sample period covers most of the recent floating exchange rate regime, from 1977M01 to 2000M12, and the start date of the sample was dictated by data availability. The data are taken from the International Monetary Fund's International Financial Statistics data base. We use the monthly industrial production index (line code 66) as a proxy for national income since gross domestic product (GDP) is available only at the quarterly frequency. ${ }^{8}$ Our measure of money is defined as the sum of money (line code 34) and quasi-money (line code 35) for the US, Canada, Japan, while for the UK we use M0. We deseasonalize the money and industrial production indices, following Mark and Sul (2001). The exchange rate is the end-of-month nominal bilateral exchange rate (line code AE). Our choice of countries reflects our intention to examine exchange rate data for major industrialized economies belonging to the G7 that have been governed by a pure float over the sample. ${ }^{9}$ As a proxy for the nominally safe (riskfree) domestic and foreign bonds, we use end-of-month Euro-market bid rates with one month maturity for each of the US, Canada, Japan and the UK, provided by the Bank for International Settlements (BIS).

The data were transformed in natural logarithms prior to beginning the empirical analysis to yield time series for $s_{t}, m_{t}, m_{t}^{*}, y_{t}$ and $y_{t}^{*}$. The monetary fundamentals series, $f_{t}$, was constructed with these data in logarithmic form according to equation (2) with $\phi=1$; and $s_{t}$ is taken as the logarithm of the domestic price of the foreign currency, with the US denoting the domestic country. In our empirical work, we use the data over the period January 1977-December 1990 for estimation, and reserve the remaining data for the out-of-sample forecasting exercise. ${ }^{10}$ In addition, the domestic and foreign interest rates are treated as constant and set equal to their historical mean.

\footnotetext{
${ }^{8}$ Note that a preliminary analysis of the statistical properties of the (quarterly) industrial production indices and GDP time series over the sample period and across the countries examined in this paper produced a coefficient of correlation higher than 0.95 .

${ }^{9}$ Note that, while Canada and Japan have experienced a free float since the collapse of the Bretton Woods system in the early 1970s, the UK was in the Exchange Rate Mechanism (ERM) of the European Monetary System (EMS) for about two years in the early 1990s. However, given the short length of this period, we consider sterling as a freely floating exchange rate in this paper. The remaining three G7 countries not investigated here, namely Germany, France and Italy, have all been part of the ERM for most of the sample period under investigation and in fact joined the European Monetary Union on 1 January 1999, when the euro replaced the national currencies of these three countries.

${ }^{10}$ It should be noted that the original Meese-Rogoff paper considered forecast horizons of up to 12 quarters ahead, while Mark (1995), for example, uses a maximum horizon of 16 quarters. In general, most studies in this literature have focused on horizons of up to 4 years ahead and therefore the forecast horizon considered in this paper is-to the best of our knowledge-the longest horizon considered in the relevant exchange rate literature to date.
} 
Before employing our approach based on utility calculations described in Section 3, we replicate, using our data, the exercise typically carried out by researchers to investigate the relationship between nominal exchange rates and monetary fundamentals. We estimate a long-horizon regression as in equation (3) using our monthly data up to December 1990 to generate forecasts for different horizons from 1 quarter ( 3 months) to 4 years ( 48 months), i.e. $k=3,12,24,36,48$. The procedure employed is identical to Mark (1995).

Table 1 presents results from this exercise with significance levels generated from a data generating process (DGP) where the fundamentals term $u_{t}$ is assumed to follow an $\operatorname{AR}(1)$ process. Out-of-sample forecasts are evaluated against the benchmark of a driftless random walk. Mark (1995) concluded that evidence of predictability-including $t$-statistics and bootstrapped $p$-values for the significance of $\beta_{k}$, the $R^{2}$, and the bootstrapped $p$-values for the significance of a Diebold-Mariano (1995) test for equal forecast accuracy-increases with the forecast horizon and that there is evidence of statistically significant predictability at horizons of 3 and 4 years only for two currencies (namely the Deutsche mark and Swiss franc, which we do not analyze in our paper). Mark (1995) found no evidence of predictability for the Canadian dollar and the Japanese yen (which we study in this paper) and did not analyze the UK sterling. We confirm that the strongest evidence of predictability is at the longest horizons on our data, recording some significant estimates of $\beta_{k}$ and $R^{2}>0.5$ at the 3 - and 4-year horizons (Table 1). However, the Diebold-Mariano (OUT/RW) statistics, computed by bootstrap under the null hypothesis of a random walk with drift, are never statistically significant at conventional significance levels. Hence,

the OUT/RW statistics - which are less than one when the monetary fundamentals forecasting regression provides a lower root mean square error (RMSE) than the random walk forecast - show that the monetaryfundamentals model does not beat the benchmark random walk model at any horizon for any of the three exchange rates examined. This confirms for our data the results in previous literature leading to the exchange rate disconnect puzzle (see the survey of Neely and Sarno, 2002, and the references therein).

\section{International Asset Allocation, Predictability and Parameter Uncertainty: Empirical Results}

We now report our empirical results based on solving the maximization problem (10), which allows us to study the implications for optimal portfolio weights when the exchange rate is either a random walk or predictable respectively, in the case with parameter uncertainty. We do not report the results for the case without parameter uncertainty below in order to conserve space, although these results are given in 
Abhyankar, Sarno and Valente (2004).

As described in Section 3, a buy-and-hold investor who takes into account parameter uncertainty and has an horizon $\widetilde{T}=1, \ldots, 10$ solves the problem in equation (10). Using a recursive Monte Carlo sampling procedure, we obtain an accurate representation of the posterior distributions of the estimated vector of parameters $\theta$. Using data till December 1990, we estimate the posterior distribution of the parameters for all countries by drawing samples of size 1,000,000. From these estimated distributions, we obtain out-of-sample forecasts for the investment horizon $\widetilde{T}=1, \ldots, 10$ years.

Figure 1, which refers to the Japanese yen, depicts the optimal weight $\omega$ (in percentage terms) allocated by a US investor to the foreign asset on the vertical axis, and the investment horizon (in years) on the horizontal axis. We show optimal weights for four different values of the coefficient of risk aversion, $A$, ranging from 2 to 20 . The solid lines correspond to the case where the investor relies on the fundamentals model (predictability). The dotted lines refer to the case where the investor uses a random walk model (no predictability). ${ }^{11}$

It is important to note one point about the variability attached to the estimate of $\omega$ obtained using this procedure. Barberis (2000) provides a detailed discussion of this issue and shows that, given the sample size used in the simulated draws $(1,000,000)$, there is no significant variation in the estimate of $\omega$. In other words, for this number of draws, the law of large numbers applies, resulting in a vanishing small variance of $\omega$. As a result, given our large number of replications, we can assume that the optimal portfolio weight $\omega$ reported in Figure 1 converges to the value that would have been obtained if we could perform the integrations exactly. Hence, in our empirical results, we do not report confidence intervals for $\omega$ given that its variability is 'virtually' zero for our number of draws (see Appendix A, Table A1, for further details).

The graphs in Figure 1 show some interesting features. First, both for the case of predictability and no predictability, the optimal weight to the foreign asset, $\omega$ is lower (in absolute value) for higher levels of risk aversion, $A$. Second, with regard to the effects of predictability versus no predictability in determining the optimal weights to the foreign asset, our results clearly indicate that the optimal weights may differ significantly in these two cases. Indeed, the difference can be so large as to imply optimal weights with different signs, as, for example, in the case of Japan (see Figure 1). ${ }^{12}$

Summing up, our results show that predictability plays an important role in the investor's choices for

${ }^{11}$ The full set of graphs for all three exchange rates examined are available in the working paper version (Abhyankar, Sarno and Valente, 2004, Figures 1-6).

${ }^{12}$ The same occurs for Canada, whereas for the UK the sign of the optimal weight is the same under predictability and no predictability, but the difference in the two corresponding weights is still sizable for higher levels of risk aversion (see 
all countries and for different values of the coefficient of risk aversion. Specifically, predictability implies different optimal weights to the foreign asset compared to no predictability. This difference can be large enough to generate weights with a different sign-meaning that when a fundamentals model implies a long (short) position in the foreign asset the random walk model may imply a short (long) position in the foreign asset.

We now turn to the core of our empirical work, a quantitative analysis of the economic value of exchange rate predictability.

\section{The Out-of-Sample Economic Value of Predictability}

This section reports our results on the economic value of predictability. We begin by calculating end-ofperiod wealth, as defined in equation (5) and normalizing its initial value $W_{T}=1$. In these calculations $\omega$ is obtained from the utility maximization problem solved in the previous section. In our context, the random walk model and the fundamentals model may be seen as reflecting two polar approaches to exchange rate forecasting. Specifically, an investor who assumes predictability (i.e. believes in the fundamentals model) considers the fundamentals model as a perfect description of reality. An investor who believes in the random walk approach assumes, on the other hand, that there is no variable able to predict the exchange rate. The wealth calculations on the basis of which we compare the two models are obtained using realized or ex post data in equation (5). ${ }^{13}$ We also calculate the realized end-of-period utilities, using equation (6), and the realized certainty equivalent returns in order to compare the outof-sample performance of the two competing models on the basis of various measures of economic and utility gains.

A related question involves the ex ante performance of each of the random walk model and the fundamentals model. In this case, the evaluation of the performance of the models would be based on an ex ante or expected end-of-period wealth calculation, where the change in the exchange rate $\Delta s_{T+\widetilde{T}}$ is the forecast of the exchange rate implied by the model being considered rather than its realized value. This calculation would provide information on the returns and on the economic value that the investor would expect given the data, the investment horizon, and her belief in a particular model. Clearly, while this exercise can be implemented out-of-sample, it implicitly assumes that the model which provides the forecasts is the true data generating process-that is, no ex post realized data are used. However, this

\footnotetext{
Figures 1-3 in Abhyankar, Sarno and Valente, 2004).

${ }^{13}$ Thus, given equation (5), the forecasts produced by each of the two models considered affect the end-of-period wealth only through the choice of the optimal weight $\omega$.
} 
is helpful as it provides an estimate of expected returns or economic value, which the investor may use in deciding whether, given her belief in the model, the investment in foreign exchange is worthwhile ex ante. It should be clear, on the other hand, that such an ex ante calculation does not address the key question in this paper, which is about the out-of-sample forecasting ability of the fundamentals model relative to a random walk model. A pure out-of-sample comparison designed to evaluate the ability of a model to match the realized data can only be done by comparing the outcome from the model-based forecasts to the ex post data, which is the approach we follow in this paper, in line with the literature on exchange rate forecasting. ${ }^{14}$

We now turn to the calculation of the ex post end-of-period wealth for the cases of predictability and no predictability. We define the following measures of economic gain (loss): (i) the wealth ratio as the ratio of the end-of-period wealth from using the fundamentals model to the end-of-period wealth from using a random walk; (ii) the utility ratio as the ratio of the end-of-period utility from the fundamentals model to the end-of-period utility from using a random walk; (iii) the differences in certainty equivalent returns (CERs) as the annualized differences between the CER calculated from the utility from the fundamentals model and the CER corresponding to the utility using a random walk. It is important to emphasize here that none of these measures of economic value has a standard error since they are based on a pure ex post out-of-sample evaluation which relies on the calculation of the end-of-period wealth given in equation (5) at time $\widetilde{T}$.

We compute the end-of-period wealth on the basis of interest rates which are known $\left(r\right.$ and $\left.r^{*}\right)$, a realized value of the change in the exchange rate at time $\widetilde{T}$, and the value of $\omega$ implied by a particular investment strategy, risk aversion parameter and model. Hence, given that $\omega$ has a variance that may be regarded as 'virtually' zero for our number of draws (see our discussion in Section 5), the end-of-period wealth obtained using equation (5) does not have an associated variance. As a consequence, given the setup of our out-of-sample forecasting exercise where there is no uncertainty associated with the outof-sample end-of-period wealth calculations, there is no available testing procedure for equal forecast accuracy and tests based on Diebold and Mariano (1995) or West (1996), West and McCracken (1998) and Clark and McCracken (2001) are not applicable-see also Appendix A for further details on this point.

In our discussion of the empirical results in this section, we focus on end-of-period wealth and wealth ratios, since the results from using the other two measures of economic value of predictability (utility ratios

\footnotetext{
${ }^{14}$ Although, as explained above, this is not directly relevant to the question addressed in this paper, as a preliminary exercise we also carry out the analysis on an ex ante basis. The results are discussed in the working paper version (Abhyankar, Sarno and Valente, 2004).
} 
and differences in CERs) are qualitatively identical, as shown in the full tables of results in Abhyankar, Sarno and Valente (2004). In Table 2, we report the end-of-period wealth for our US investor over the period January 1991-December 2000 for each of the Canadian dollar, Japanese yen and UK sterling. The results show the economic values and gains for different investment horizons $\widetilde{T}=1, \ldots, 5,10$ and for different coefficients of risk aversion $(A=2,5,10,20)$. For a given coefficient of risk aversion, Table 2 reports the end-of-period wealth and (in parentheses) the wealth ratios. Our results show that predictability using monetary fundamentals is, in general, of incremental economic value above that for a random walk specification. For example, in the case of Canada, the wealth ratio is greater than unity at all horizons longer than one year, indicating that at all horizons longer than one year the end-of-period wealth achieved from using the fundamentals model is higher than the end-of-period wealth attained from using a random walk. In the case of Japan, for all values of $A$ considered, the end-of-period wealth under predictability is much higher than that for a naive no-change investor. For example, for $A=2$ the wealth ratio ranges from a low of 1.08 at the one-year horizon to a high of 1.43 at the ten-year horizon. The effects of predictability are dramatically reduced for a very risk averse investor $(A=20)$, with a wealth ratio ranging from 1.01 at the one-year horizon to a high of 1.05 at the ten-year horizon. For the UK, however, the use of predictability does not seem to be economically important for $A=2$, although for a more risk averse investor there is some gain from using the monetary fundamentals model compared with using a naive random walk model at long horizons.

It is interesting to note that, in general, our results are not very sensitive to the length of the investment horizon for a low level of risk aversion. The results in Table 2 also show that it is mainly at horizons longer than one year that monetary fundamentals predict future nominal exchange rates better than a naive random walk. However, we find that the wealth ratio is often greater than unity even for relatively short horizons such as $\widetilde{T}=2$ and occasionally even for $\widetilde{T}=1$, which is in sharp contrast with the conventional wisdom that monetary fundamentals can forecast the exchange rate only at horizons as long as 4 or 5 years ahead. In the case of more risk averse investors $(A=20)$, the results are qualitatively similar.

However, note that, while wealth increases monotonically with the investment horizon both under predictability and no predictability, the wealth ratio measuring the gain from using the fundamentals model does not increase monotonically over the investment horizon. Nevertheless, it is notable that the return at the end of the 10-year investment horizon from employing a fundamentals model is relatively large, at least 120, 102 and 137 percent for Canada, Japan and the UK respectively.

Overall, these results provide evidence of economic value to exchange rate predictability across coun- 
tries and for a range of values of the coefficient of risk aversion. This is clear from the fact that the end-of-period wealth achieved by the investor who assumes that the exchange rate is predictable is higher than that obtained by the investor who assumes that the exchange rate follows a random walk. The order of magnitude varies across countries and with the coefficient of risk aversion. In particular, we find that the difference between end-of-period wealth under predictable and unpredictable exchange rate changes is lower for higher levels of risk aversion. However, taken together, the results that the wealth ratio increases non-monotonically and that the return from employing a fundamentals model is large imply that the return from a random walk is also large in terms of economic value. This confirms the stylized fact that a random walk model is a very difficult benchmark to beat, even when the assessment of its predictive power is based on economic criteria. ${ }^{15}$

We find that the gain from using a fundamentals model is positively related to the investment horizon and negatively related to the level of risk aversion. Of course, the results are obtained on a particular sample period for estimation and for out-of-sample prediction, so that our claims are subject to the caveat that they may be sample specific. Nevertheless, for the sample period we investigate, the evidence we present suggests that an investor using a fundamentals model in 1990 to take positions in domestic and foreign assets would have been better off than an investor using a random walk model.

\section{$7 \quad$ Extensions and Robustness}

There are a number of ways in which this study could be extended. First, one obvious concern is that our results may be sample specific. Our choice of exchange rates and sample period reflects our intention to focus on freely floating exchange rates over the post-Bretton Woods period and follows much previous research in the literature on exchange rate forecasting. Testing the robustness of our findings using other exchange rate data and/or sample periods is a logical extension. Second, we consider here a simple case where the investor allocates wealth between two assets; a more realistic scenario would be to allow for multiple assets. However, while this will require more complex estimation techniques, it would also take us away from the main point of this paper, which is to draw attention to the economic value of

\footnotetext{
${ }^{15}$ An extreme case is the UK for $A=2$ (Panel $\mathrm{C}$ of Table 2), where we report a wealth ratio of unity over the whole investment horizon. This is of course due to the fact that the optimal weights are the same under each of predictability and no predictability in this case. Generally, although for the UK we record high returns in absolute terms from assuming predictability, these returns are not much larger than the returns obtained using a random walk specification. This result seems consistent with the difficulty to forecast the UK sterling during the 1990s often recorded in the literature even in studies where time-series models are found to beat a random walk (e.g. see Clarida, Sarno, Taylor and Valente, 2003).
} 
exchange rate forecasting models. Third, we use a simple power utility set up to illustrate our main point. However, in the context of an international investor, the use of other utility functions, such as those that allow for ambiguity aversion or habit formation, may also be of great interest.

In this sub-section we discuss two further extensions we carried out. First, we consider an investor who adopts a slightly more sophisticated strategy than the static buy-and-hold strategy studied above. Specifically, we analyze the case of an investor who optimally re-balances her portfolio at the end of every period using exchange rate forecasts based on the monetary-fundamentals model. We again analyze the optimal allocation under parameter uncertainty. In this multi-period asset allocation problem, the optimal weights are now the solution to a dynamic programming problem that can be solved by discretizing the state space and using backward induction-for technical details on the numerical methods used to solve this dynamic programming problem and for detailed empirical results, see the working paper version (Abhyankar, Sarno and Valente, 2004). ${ }^{16}$

With respect to the asset allocation problem, we find that the optimal allocation under dynamic rebalancing is qualitatively similar to the allocation implied by the static buy-and-hold strategy. Further, with respect to the forecasting results for an investor who uses a dynamic rebalancing strategy, we calculate the end-of-period wealth (and the relevant wealth ratio, the utility ratio and the difference in CERs) for this case over an investment horizon of ten years. The results confirm, in general, the predictive ability of the monetary fundamentals model and also suggest that the dynamic rebalancing strategy leads to worse outcomes relative to a static buy-and-hold strategy for a forecast horizon of 10 years.

At first glance, one might argue that the latter result is puzzling since it is always possible for the dynamic strategy to mimic the static strategy. In essence, the two strategies have the same weight at the end of the investment horizon $T+\widetilde{T}$. However, while the static strategy results in the same weight throughout the investment horizon, the dynamic strategy chooses weights by backward induction from time $T+\widetilde{T}$ to time $T+1$; the weight is adjusted depending on the predicted path of the exchange rate between time $T$ and $T+\widetilde{T}$. Therefore, in the dynamic strategy, maximization of expected utility

\footnotetext{
${ }^{16}$ Evaluating the joint dynamics of the state variables as well as the parameters in the model is a non-trivial dynamic programming problem. It is useful therefore to make some reasonable simplifying assumptions so that this task is numerically tractable. The dimensionality of the problem is reduced by assuming that the investor's beliefs about the parameters of the model do not change from what they are at the beginning of the investment horizon. In other words, these beliefs are summarized by the posterior distribution calculated conditional only on the data observed at the beginning of the investment horizon.
} 
occurs on the basis of the period-by-period predictive distributions of the exchange rate, whereas the static strategy maximizes expected utility on the basis of the $\widetilde{T}$-period predictive distribution of the exchange rate. This implies that, ex ante, when one knows or assumes the true data generating process of the exchange rate (and hence its distribution is known), the investor would always prefer the dynamic strategy to the static one. This is not necessarily true ex post and, in fact, in our ex post evaluation over the sample period and exchange rates examined, the dynamic strategy performs worse than the static one. Our interpretation of this result is that, while the exchange rate forecasts are accurate at long horizons, as indicated by the evidence that the fundamentals model beats a random walk model for both dynamic and static strategies, the predicted dynamic adjustment path of the exchange rate towards its forecast at the end of the horizon $T+\widetilde{T}$ may be poor. This is not surprising since the model used for forecasting exchange rates with fundamentals is a classic long-horizon regression which does not attempt to model the short-run dynamics. Clearly, a richer specification of the short-run exchange rate dynamics in our empirical model might well yield the result that the dynamic strategy makes the investor better off relative to a static strategy. To sum up, what we take from the result that ex post the dynamic strategy performs worse than the static strategy in our data set is that if one uses a long-horizon regression out of sample the gain from using a dynamic strategy rather than a static one is not obvious. ${ }^{17}$

A second extension of our empirical work we undertake involves the analysis of an 'augmented' fundamentals model. Specifically, in addition to the conventional fundamentals used in the vast majority of studies in this literature-money supply differentials and income differentials, as captured by the term $u_{t}$ in equations (1)-(2)-we employed in the information set the net position in foreign assets between the US and the relevant foreign country, say NFA. This variable is predicted to enter the steady state equation for the nominal exchange rate in some recent NOEM models based on an overlapping generations structure (e.g. see Cavallo and Ghironi, 2002). The VAR for the fundamentals investor now becomes a

\footnotetext{
${ }^{17}$ Also, this result may be due to our choice of the rebalancing period, assumed to be one year. This may be suboptimal in light of the evidence that fundamentals are most powerful at predicting the exchange rate in the medium to long run, say 3 or 4 years (e.g., Mark, 1995). In principle, one would expect that the optimal rebalancing period is a function of the speed at which the exchange rate change adjusts to restore deviations of the exchange rate from its fundamental value in a way that the rebalancing is carried out over the horizon where the predictive power of the deviations from fundamentals is at its peak. Given the large amount of evidence in the literature (e.g., Mark, 1995; Mark and Sul, 2001) that the predictive power of monetary fundamentals is higher at medium to longer horizons one would expect the optimal dynamic rebalancing period to be somewhat longer than one year. Rules of selection of the optimal rebalancing period are not investigated in this paper, but we consider this issue as an immediate avenue for future research.
} 
three-equation model where the first equation has as an additional regressor $N F A_{t}$, the second equation remains an $\operatorname{AR}(1)$ model for $u_{t}$, and the third equation is an $\operatorname{AR}(1)$ model for $N F A_{t}{ }^{18}$

For this augmented fundamentals model we then solved the static buy-and-hold optimization problem and performed an out-of-sample forecasting exercise, replicating step by step the analysis carried out earlier for the buy-and-hold problem examined in Sections 5-6. The results of the forecasting exercise are given in Table 3, where we report our findings only for $A=2,20$ to conserve space. These results are qualitatively similar to the results obtained for the canonical monetary fundamentals, indicating that this fundamentals model provides incremental economic gains relative to the random walk model that are positively related to the investment horizon and negatively related to the level of risk aversion. Quantitatively, we find that for Canada and the UK, the augmented fundamentals model performs almost identically to the canonical fundamentals model, yielding virtually identical end-of-period wealth. However, for Japan, the canonical fundamentals model yields a higher end-of-period wealth than the augmented model with net foreign assets, suggesting that in this case the addition of this extra predictor variable leads to worse asset allocation decisions and hence lower utility. On balance, our results provide scant prima facie evidence for the case of adding net foreign assets to the canonical fundamentals model. ${ }^{19}$

\section{Conclusion}

Meese and Rogoff (1983) first noted that standard structural exchange rate models are unable to outperform a naive random walk model in out-of-sample exchange rate forecasting, even with the aid of ex post data. Despite the increasing sophistication of the econometric techniques employed and the quality of

\footnotetext{
${ }^{18}$ For this exercise, we used data on net foreign positions in equities and bonds taken from the International Capital Reports of the US Treasury Department. Quarterly data are regularly published in the US Treasury Bulletin, while monthly data are available on the website of the US Treasury Department. Most of these data are collected by the US Treasury from financial intermediaries in the US through the International Capital Form $\mathrm{S}$ reports. Our measure of $N F A$ is calculated as the difference between the log-detrended purchases and sales of foreign assets, consistent with the definition of Cavallo and Ghironi (2002, p. 1074).

${ }^{19}$ Since models in the NOEM tradition typically have consumption-rather than income-in the steady state equation for the exchange rate, we also experimented with replacing our income differential in $u_{t}$ with the differential in consumption of nondurables and services or total consumption. However, this forecasting exercise-carried out at quarterly frequency since data for consumption are not available at monthly frequency-did not produce any empirical evidence favoring the use of consumption rather than income in our fundamentals predictive model (results available upon request).
} 
the data sets utilized, the original results highlighted by Meese and Rogoff continue to present a challenge and constitute a component of what Obstfeld and Rogoff (2000) have recently termed as the 'exchange rate disconnect puzzle.'

Prior research in this area has largely relied on statistical measures of forecast accuracy. Our study departs from this in that we focus instead on the metric of economic value to an investor in order to assess the performance of fundamentals models. This is particularly important given the several cumbersome econometric issues that plague statistical inference in this literature. Our paper provides the first evidence on the economic value of the exchange rate forecasts provided by an exchange rate-monetary fundamentals framework. Specifically, we compare the economic value, to a utility maximizing investor, of out-of-sample exchange rate forecasts using a monetary-fundamentals model with the economic value under a naive random walk model. We assume that our investor faces the problem of choosing how much she will invest in two assets that are identical in all respects except the currency of denomination. This problem is studied in a Bayesian framework that explicitly allows for parameter uncertainty.

Our main findings are as follows. First, predictability substantially affects, both quantitatively and qualitatively, the choice between domestic and foreign assets for all currencies and across different levels of risk aversion. Specifically, exchange rate predictability (characterized using the monetary-fundamentals model) can yield optimal weights to the foreign asset that may be very different (in magnitude and, sometimes, in sign) from the optimal weights obtained under a random walk model. Second, and more importantly, our results lend some support for the predictive ability of the exchange rate-monetary fundamentals model. This finding holds for the three major exchange rates examined in this paper using data for the modern floating exchange rate regime. The gain from using the information in fundamentals in order to predict the exchange rate out of sample (as opposed to assuming that the exchange rate follows a random walk) is often substantial, although it varies somewhat across countries. We find that the gain from using a fundamentals model is, in general, positively related to the investment horizon and negatively related to the level of risk aversion. In turn, these findings suggest that the case against the predictive power of monetary-fundamentals models may have been overstated. 


\section{A Technical Appendix on Numerical Methods}

This appendix provides details of the Bayesian econometric approach used in our paper. Specifically, we describe the computations used in the optimization problem presented in Section 3.1.

First, we assume that the exchange rate is a random walk with drift: $\Delta s_{t}=\mu+\varepsilon_{t}$, where $\Delta s_{t}$ is the log-difference of the end-of-period nominal exchange rate, and $\Delta$ is the first-difference operator; and $\varepsilon_{t}$ $\sim \operatorname{iidN}\left(0, \sigma^{2}\right)$. We incorporate parameter uncertainty by using the predictive distribution of the nominal exchange rate, $p\left(\Delta_{\widetilde{T}} s_{T+\widetilde{T}} \mid \Delta s\right)$, where $\Delta s$ is the vector of observed nominal exchange rate changes over the sample period. In the case without parameter uncertainty, on the other hand, we compute the expected value over the distribution of the future nominal exchange rate conditional on fixed parameters values, $p\left(\Delta_{\widetilde{T}} s_{T+\widetilde{T}} \mid \Delta s, \widehat{\mu}, \widehat{\sigma}^{2}\right)$. In both cases, the conditional distribution of the nominal exchange rate is a normal distribution. Under no parameter uncertainty, $p\left(\Delta_{\widetilde{T}} s_{T+\widetilde{T}} \mid \Delta s, \widehat{\mu}, \widehat{\sigma}^{2}\right)$ is a normal distribution, $N\left(\widetilde{T} \widehat{\mu}, \widetilde{T} \widehat{\sigma}^{2}\right)$, where $\widehat{\mu}$ and $\widehat{\sigma}^{2}$ denote the estimates of the mean and variance calculated over the sample period. When parameter uncertainty is accounted for, $p\left(\Delta_{\widetilde{T}} s_{T+\widetilde{T}} \mid \Delta s\right)$ is obtained using the value of the parameters $\mu$ and $\sigma^{2}$ obtained by iterative sampling from the marginal posterior distributions under a noninformative prior (that is, $\left.p\left(\mu, \sigma^{2}\right) \propto \frac{1}{\sigma^{2}}\right) .^{20}$

Second, we consider the case when the exchange rate is predictable, that is the model is a VAR of the form $z_{t}=a+B x_{t-1}+\eta_{t}$, where $z_{t}^{\prime}=\left(\Delta s_{t}, x_{t}^{\prime}\right), x_{t}=\left(x_{1, t}, x_{2, t}, \ldots, x_{n, t}\right)^{\prime}$, and $\eta_{t} \sim \operatorname{iidN}(0, \Sigma)$. The vector of explanatory variables $x_{t}$ are used for predicting the exchange rate. Here too we consider the effects of accounting for parameter uncertainty. In particular, under no parameter uncertainty, $p\left(z_{T+\widetilde{T}} \mid z, \widehat{a}, \widehat{B}, \widehat{\Sigma}\right)$ is a bivariate normal distribution, $N_{2}(\widehat{\widehat{\mu}}, \widehat{\widehat{\Sigma}})$, where

$$
\begin{aligned}
\widehat{\widehat{\mu}}= & \widetilde{T} \widehat{a}+(\widetilde{T}-1) \widehat{B}_{0} \widehat{a}+(\widetilde{T}-2) \widehat{B}_{0}^{2} \widehat{a}+\ldots+\widehat{B}_{0}^{\widetilde{T}-1} \widehat{a}+\left(\widehat{B}_{0}+\ldots+\widehat{B}_{0}^{\widetilde{T}}\right) z_{T} \\
\widehat{\widehat{\Sigma}}= & \widehat{\Sigma}+\left(I+\widehat{B}_{0}\right) \widehat{\Sigma}\left(I+\widehat{B}_{0}\right)^{\prime}+\ldots+ \\
& \left(I+\widehat{B}_{0}+\ldots+\widehat{B}_{0}^{\widetilde{T}-1}\right) \widehat{\Sigma}\left(I+\widehat{B}_{0}+\ldots+\widehat{B}_{0}^{\widetilde{T}-1}\right)^{\prime}
\end{aligned}
$$

and $\widehat{a}, \widehat{B}, \widehat{\Sigma}$ are estimates of the parameters in the VAR $z_{t}=a+B x_{t-1}+\eta_{t}$, obtained over the sample

\footnotetext{
${ }^{20}$ In other words, in order to get a sample $\left\{\Delta_{\widetilde{T}}^{(i)} s_{T+\widetilde{T}}\right\}_{i=1}^{M}$ from the two possible distributions, we draw $M$ times from the normal distribution $N\left(\widetilde{T} \widehat{\mu}, \widetilde{T} \widehat{\sigma}^{2}\right)$ in the case of no parameter uncertainty; in the case of parameter uncertainty we draw $M$ times from the normal distribution $N\left(\widetilde{T} \widehat{\mu}^{(i)}, \widetilde{T} \widehat{\sigma}^{2(i)}\right)$, where $\widehat{\mu}^{(i)}, \widehat{\sigma}^{2(i)}$ are values from the $i$ th draw from $p\left(\sigma^{2} \mid \Delta s\right)$ and $p\left(\mu \mid \sigma^{2}, \Delta s\right)$. The posterior distribution of the parameters conditional upon the data $p\left(\mu, \sigma^{2} \mid \Delta s\right)$ can be obtained by first sampling from the marginal distribution, $p\left(\sigma^{2} \mid \Delta s\right)$, an inverse Gamma distribution, and then, given the draw for the variance, from the conditional distribution $p\left(\mu \mid \sigma^{2}, \Delta s\right)$, which is a normal distribution. See Zellner (1971).
} 
period used; $\widehat{B}_{0}$ is a matrix obtained by adding an initial vector of zeros to $\widehat{B}$; and $I$ is the identity matrix. If parameter uncertainty is taken into account, $p\left(z_{T+\widetilde{T}} \mid z\right)$ is computed using the value of the estimated parameters $\widehat{a}, \widehat{B}, \widehat{\Sigma}$ obtained by iterative sampling from the marginal posterior distributions under a noninformative prior (that is, $\left.p(a, B, \Sigma) \propto|\Sigma|^{-(n+2) / 2}\right):^{21}$

$$
\begin{aligned}
\widehat{\mu}= & \widetilde{T} \widehat{a}^{(i)}+(\widetilde{T}-1) \widehat{B}_{0}^{(i)} \widehat{a}^{(i)}+(\widetilde{T}-2) \widehat{B}_{0}^{2(i)} \widehat{a}^{(i)}+\ldots+\widehat{B}_{0}^{\widetilde{T}-1(i)} \widehat{a}^{(i)}+\left(\widehat{B}_{0}^{(i)}+\ldots+\widehat{B}_{0}^{\widetilde{T}(i)}\right) z_{T} \\
\widehat{\widehat{\Sigma}}= & \widehat{\Sigma}^{(i)}+\left(I+\widehat{B}_{0}^{(i)}\right) \widehat{\Sigma}^{(i)}\left(I+\widehat{B}_{0}^{(i)}\right)^{\prime}+\ldots+ \\
& +\left(I+\widehat{B}_{0}^{(i)}+\ldots+\widehat{B}_{0}^{\widetilde{T}-1(i)}\right) \widehat{\Sigma}^{(i)}\left(I+\widehat{B}_{0}^{(i)}+\ldots+\widehat{B}_{0}^{\widetilde{T}-1(i)}\right)^{\prime}
\end{aligned}
$$

for $i=1, \ldots, M$, where $\widehat{a}^{(i)}, \widehat{B}_{0}^{(i)}, \widehat{\Sigma}^{(i)}$ are values from the $i$ th draw from $p\left(\Sigma^{-1} \mid z\right)$ and $p(\operatorname{vec}(a, B) \mid \Sigma, \Delta s)$. By computing $p\left(z_{T+\widetilde{T}} \mid z, a, B, \Sigma\right)$ and $p\left(z_{T+\widetilde{T}} \mid z\right)$, we are able to extract a sample $\left\{\Delta_{\widetilde{T}}^{(i)} s_{T+\widetilde{T}}\right\}_{i=1}^{M}$ which represents the future expected nominal exchange rate for the horizon $\widetilde{T}$ under predictability, without and with parameter uncertainty respectively.

Finally, we approximate the integrals for expected utility in equations (8) and (11) by using the sample $\left\{\Delta_{\widetilde{T}}^{(i)} s_{T+\widetilde{T}}\right\}_{i=1}^{M}$ and then computing $\frac{1}{M} \sum_{i=1}^{M} \frac{\left[(1-\omega) \exp (r \widetilde{T})+\omega \exp \left(r^{*} \widetilde{T}+\Delta_{\widetilde{T}}^{(i)} s_{T+\widetilde{T}}\right)\right]^{1-A}}{1-A}$.

The results reported in the paper refer to a sample size of $M=1,000,000$ and were produced using an initial value of the predictor variables vector (in our case simply $u_{t}$ as defined in equations (1)-(2)) equal to its historical mean. In order to evaluate the accuracy of the numerical methods used, we carried out the following exercise. We first calculated the expected utility and, therefore, the optimal allocation to the foreign asset $\omega$ over the investment horizon spanning from 1 and 10 years, using 50 independent samples of 100 draws each from the sampling distributions. We then repeated the same calculation using 50 independent samples of 1,000,10,000,100,000 and 1,000,000 draws. The averages and standard deviations of the optimal allocation to the foreign asset $\omega$ are reported in Table A1. The results, which may be seen as representative of results from any other exchange rate and risk aversion parameter, relate to the US dollar-Japanese yen exchange rate with a coefficient of risk aversion $A=5$.

The results in Table A1 clearly indicate that, the larger the number of draws, the smaller is the uncertainty (i.e. standard deviation) surrounding the average optimal asset allocation $\omega$. In particular for a number of draws $M$ equal to or greater than 100,000 the standard deviation is quite close to zero, and for $M=1,000,000$ it is virtually zero. As in Barberis (2000), one caveat to this exercise is that the standard deviation of the estimate of the optimal portfolio may fall faster then its bias, i.e. the

\footnotetext{
${ }^{21}$ The posterior distribution of the parameters conditional upon the data is obtained in this case by first sampling from the marginal distribution $p\left(\Sigma^{-1} \mid z\right)$, a Wishart distribution, and then, given the draws for the variance-covariance matrix, from the conditional distribution $p(\operatorname{vec}(a, B) \mid \Sigma, \Delta s)$, which is a multivariate normal distribution (see Zellner, 1971).
} 
distribution of the recommended portfolios may not be centered at the same point. Although we cannot rule out this possibility, there does not seem to be evidence of bias in the estimate of the optimal portfolio even using relatively small samples of 50 replications.

Table A1. Accuracy of the numerical methods

\begin{tabular}{lllllll}
\hline \hline \multicolumn{1}{r}{$\widetilde{T}=$} & 1 & 2 & 3 & 4 & 5 & 10 \\
& & & & & & \\
\hline$M=100$ & 27 & 28 & 28 & 29 & 31 & 25 \\
& $(54)$ & $(36)$ & $(33)$ & $(31)$ & $(19)$ & $(11)$ \\
$M=1,000$ & 28 & 30 & 27 & 30 & 29 & 27 \\
& $(17)$ & $(13)$ & $(9)$ & $(7)$ & $(6)$ & $(7)$ \\
$M=10,000$ & 29 & 28 & 28 & 27 & 28 & 27 \\
& $(5)$ & $(4)$ & $(3)$ & $(3)$ & $(3)$ & $(2)$ \\
$M=100,000$ & 29 & 27 & 29 & 28 & 28 & 27 \\
& $(2)$ & $(2)$ & $(2)$ & $(1)$ & $(1)$ & $(1)$ \\
$M=1,000,000$ & 29 & 26 & 31 & 28 & 27 & 27 \\
& $(0)$ & $(0)$ & $(0)$ & $(0)$ & $(0)$ & $(0)$ \\
\hline
\end{tabular}

Notes: The table presents the optimal weight $\omega$ (in percentage terms) to the foreign asset for different investment horizons ( $\widetilde{T}=1, \ldots, 5,10)$ for 50 different samples containing $M$ draws each. Values reported are averages and standard deviations (in parenthesis), calculated over the 50 different samples. The exercise is calibrated on the US/Japan static buy-and-hold strategy with risk aversion $A=5$. The table shows the optimal weight $\omega$ to the foreign asset. 0 denotes standard deviations smaller than $10^{-3}$. 


\section{References}

Abhyankar, A., Sarno, L. and Valente, G. 2004. Exchange Rates and Fundamentals: Evidence on the Economic Value of Predictability. Centre for Economic Policy Research Discussion Paper No. 4365.

Andrews, D.W.K. 1991. Heteroskedasticity and Autocorrelation Consistent Covariance Matrix Estimation. Econometrica, 59, 817-58.

Avramov, D. 2002. Stock Return Predictability and Model Uncertainty. Journal of Financial Economics, 64, 423-58.

Barberis, N. 2000. Investing for the Long Run When Returns Are Predictable. Journal of Finance, $55,225-64$.

Baks, K., Metrick, A. and Wachter, J.A. 2001. Should Investors Avoid All Actively Managed Mutual Funds? A Study in Bayesian Performance Evaluation. Journal of Finance, 56, 45-85.

Bauer, G. 2001. Conditional Currency Hedging and Asset Market Shocks. University of Rochester, mimeo.

Bekaert, G. and Hodrick, R.J. 1992. Characterizing Predictable Components in Excess Returns on Equity and Foreign Exchange Markets. Journal of Finance, 47, 467-509.

Berkowitz, J. and Giorgianni, L. 2001. Long-Horizon Exchange Rate Predictability?. Review of Economics and Statistics, 83, 81-91.

Campbell, J.Y. 1991. A Variance Decomposition for Stock Returns. Economic Journal, 101, 157-79.

Campbell, J.Y., Viceira, L. and White, J. 2003. Foreign Currency for Long-Term Investors. Economic Journal, 113, C1-C25.

Cavallo, M. and Ghironi, F. 2002. Net Foreign Assets and the Exchange Rate: Redux Revived. Journal of Monetary Economics, 49, 1057-97.

Cheung, Y.-W., Chinn, M.D. and Pascual, A.G. 2003. Recent Exchange Rate Models: In-Sample Fit and Out-of-Sample Performance, in: De Grauwe, P. (ed.), Exchange Rate Modeling: Where Do Stand?, Cambridge and New York: Cambridge University Press.

Clarida, R.H., Sarno, L., Taylor, M.P. and Valente, G. 2003. The Out-of-Sample Success of Term Structure Models as Exchange Rate Predictors: One Step Beyond. Journal of International Economics, $60,61-83$.

Clark, T.E. and McCracken, M.W. 2001. Tests of Forecast Accuracy and Encompassing for Nested Models. Journal of Econometrics, 105, 85-110.

Cremers, M. 2002. Stock Return Predictability: A Bayesian Model Selection Perspective. Review of 
Financial Studies, 15, 1223-49.

Diebold, F.X. and Mariano, R.S. 1995. Comparing Predictive Accuracy. Journal of Business and Economic Statistics, 13, 253-65.

Engel, C. and West, K.D. 2002. Exchange Rates and Fundamentals. University of Wisconsin and National Bureau of Economic Research, mimeo.

Faust, J., Rogers, J.H. and Wright, J. 2003. Exchange Rate Forecasting: The Errors We've Really Made. Journal of International Economics, 60, 35-59.

Frenkel, J.A. 1976. A Monetary Approach to the Exchange Rate: Doctrinal Aspects and Empirical Evidence. Scandinavian Journal of Economics, 78, 200-24.

Frenkel, J.A. and Johnson, H.A. 1978. The Economics of Exchange Rates: Selected Studies, Reading, Mass.: Addison-Wesley.

Groen, J.J.J. 2000. The Monetary Exchange Rate Model as a Long-Run Phenomenon. Journal of International Economics, 52, 299-319.

Hodrick, R.J. 1992. Dividend Yields and Expected Stock Returns: Alternative Procedures for Inference and Measurement. Review of Financial Studies, 5, 357-86.

Kandel, S. and Stanbaugh, R.F. 1996. On the Predictability of Stock Returns: An Asset-Allocation Perspective. Journal of Finance, 51, 385-424.

Karolyi, G.A. and Stulz, R.M. 2003. Are Financial Assets Price Locally or Globally? In: Constantinides, G., Harris, M. and Stulz, R.M. (eds.) Handbook of Economics of Finance, Vol. 1B, Chapter 16.

Kilian, L. 1999. Exchange Rates and Monetary Fundamentals: What Do We Learn from LongHorizon Regressions?. Journal of Applied Econometrics, 14, 491-510.

Lane, P.R. 2001. The New Open Economy Macroeconomics: A Survey. Journal of International Economics, 54, 235-66.

Leitch, G. and Tanner, J.E. 1991. Economic Forecast Evaluation: Profits Versus the Conventional Measures. American Economic Review, 81, 580-90.

Lewis, K.K. 1989. Changing Beliefs and Systematic Rational Forecast Errors with Evidence from Foreign Exchange. American Economic Review, 79, 621-36.

Lewis, K.K. 1995. Puzzles in International Financial Markets. In: Grossman, G.M. and Rogoff, K. (eds.), Handbook of International Economics, Vol. 3, Amsterdam: Elsevier, North-Holland.

Lucas, R.E. Jr. 1982. Interest Rates and Currency Prices in a Two-Country World. Journal of Monetary Economics, 10, 335-59. 
Lyons, R.K. 2001. The Microstructure Approach to Exchange Rates, Cambridge, Mass.: MIT Press.

Mark, N.C. 1995. Exchange Rates and Fundamentals: Evidence on Long-Horizon Predictability. American Economic Review, 85, 201-18.

Mark, N.C. and Sul, D. 2001. Nominal Exchange Rates and Monetary Fundamentals: Evidence from a Small Post-Bretton Woods Panel. Journal of International Economics, 53, 29-52.

Meese, R.A. and Rogoff, K. 1983. Empirical Exchange Rate Models of the Seventies: Do They Fit Out of Sample? Journal of International Economics, 14, 3-24.

Mussa, M. 1976. The Exchange Rate, the Balance of Payments and Monetary and Fiscal Policy under a Regime of Controlled Floating. Scandinavian Journal of Economics, 78, 229-48.

Mussa, M. 1979. Empirical Regularities in the Behaviour of Exhange Rates and Theories of the Foreign Exchange Market. Carnegie-Rochester Conference Series on Public Policy, 11, 9-57.

Neely, C.J. and Sarno, L. 2002. How Well Do Monetary Fundamentals Forecast Exchange Rates? Federal Reserve Bank of St. Louis Review, 84, 51-74.

Newey, W. K. and West, K. 1987. A Simple, Positive Semi-definite, Heteroskedasticity and Autocorrelation Consistent Covariance Matrix. Econometrica, 55, 703-708.

Obstfeld, M. and Rogoff, K. 1995. Exchange Rate Dynamics Redux. Journal of Political Economy, $103,624-60$.

Obstfeld, M. and Rogoff, K. 2000. The Six Major Puzzles in International Macroeconomics: Is there a Common Cause?, in: Bernanke, B. and Rogoff, K. (eds.), NBER Macroeconomics Annual 2000, Cambridge, Mass: MIT Press, 339-90.

Paye, B.S. 2004. Essays on Stock Return Predictability and Portfolio Allocation. University of California, San Diego, unpublished PhD dissertation.

Rapach, D.E. and Wohar, M.E. 2002. Testing The Monetary Model of Exchange Rate Determination: New Evidence From a Century of Data. Journal of International Economics, 58, 359-85.

Sarno, L. 2001. Toward a New Paradigm in Open Economy Modeling: Where Do We Stand? Federal Reserve Bank of St. Louis Review 83, 21-36.

Sarno, L., Valente, G. and Wohar, M.E. 2004. Monetary Fundamentals and Exchange Rate Dynamics Under Different Nominal Regimes. Economic Inquiry, 42, 477-97.

Shanken, J. and Tamayo, A. 2001. Risk, Mispricing, and Asset allocation: Conditioning on Dividend Yield. National Bureau of Economic Research Working Paper No. 8666.

West, K.D. 1996. Asymptotic Inference About Predictive Ability. Econometrica, 64, 1067-84.

West, K.D., Edison, H.J. and Cho, D. 1993. A Utility-Based Comparison of Some Models of Exchange 
Rate Volatility. Journal of International Economics, 35, 23-45.

West, K.D. and McCracken, M.W. 1998. Regression-Based Tests of Predictive Ability. International Economic Review, 39, 817-40.

Xia, Y. 2001. Learning About Predictability: The Effects of Parameter Uncertainty on Dynamic Asset Allocation. Journal of Finance, 56, 205-46.

Zellner, A. 1971. An Introduction to Bayesian Inference in Econometrics, NY: John Wiley and Sons. 
Table 1. Regression estimates and out-of-sample forecast evaluation

\begin{tabular}{lcccccc}
\hline \hline$k$ & $\widehat{\beta}_{k}$ & $t(N W)$ & $M S L-p$ & $R^{2}$ & $O U T / R W$ & $D M(A)$ \\
\hline \multicolumn{7}{c}{ Canada } \\
3 & -0.023 & -1.087 & 0.371 & 0.015 & 0.988 & 0.357 \\
12 & -0.147 & -2.399 & 0.202 & 0.117 & 0.892 & 0.290 \\
24 & -0.510 & -6.040 & 0.052 & 0.484 & 0.737 & 0.234 \\
36 & -0.857 & -13.521 & 0.006 & 0.811 & 0.548 & 0.188 \\
48 & -1.025 & -25.573 & 0.001 & 0.931 & 0.404 & 0.151 \\
\multicolumn{7}{c}{ Japan } \\
3 & -0.044 & -1.222 & 0.122 & 0.035 & 0.986 & 0.304 \\
12 & -0.243 & -2.916 & 0.046 & 0.219 & 0.897 & 0.241 \\
24 & -0.474 & -5.210 & 0.015 & 0.483 & 0.721 & 0.161 \\
36 & -0.687 & -7.075 & 0.006 & 0.654 & 0.546 & 0.160 \\
48 & -0.839 & -11.969 & 0.003 & 0.778 & 0.533 & 0.315 \\
& \multicolumn{7}{c}{ UK } \\
3 & -0.050 & -1.432 & 0.174 & 0.040 & 1.073 & 0.061 \\
12 & -0.210 & -2.454 & 0.148 & 0.154 & 1.172 & 0.165 \\
24 & -0.458 & -5.049 & 0.136 & 0.353 & 1.048 & 0.376 \\
36 & -0.778 & -10.668 & 0.043 & 0.662 & 0.987 & 0.609 \\
48 & -1.019 & -17.427 & 0.001 & 0.905 & 1.005 & 0.306 \\
\hline
\end{tabular}

Notes: The table presents ordinary least squares estimates of the parameter $\widehat{\beta}_{k}$ in equation (3) and ratios of the RMSE for the regression's out-of-sample forecasts (OUT) to the RMSE of a driftless random walk (RW). $t(N W)$ and $R^{2}$ denote $t$-statistics for the parameter $\widehat{\beta}_{k}$ and coefficients of determination of each equation respectively. $t$-statistics are calculated by using an heteroskedasticity and autocorrelation consistent variance-covariance matrix of errors (Newey and West, 1987). $M S L-p$ and $D M(A)$ are marginal significance levels for the one-tail test of the $t$-statistics $t(N W)$ and the Diebold-Mariano (1995) statistics, respectively. The Diebold-Mariano statistics has been calculated by using Andrews' (1991) univariate AR(1) rule as in Mark (1995). Marginal significance levels $M S L-p$ and $D M(A)$ are calculated by parametric bootstrap. 
Table 2. The economic value of predictability: the monetary fundamentals model

Panel A) Canada

\begin{tabular}{|c|c|c|c|c|c|c|}
\hline$\widehat{T}=$ & 1 & 2 & 3 & 4 & 5 & 10 \\
\hline \multicolumn{7}{|c|}{$A=2$} \\
\hline & $\begin{array}{l}1.0844 \\
(0.96)\end{array}$ & $\begin{array}{l}1.2167 \\
(1.04)\end{array}$ & $\begin{array}{l}1.3241 \\
(1.05) \\
A=5\end{array}$ & $\begin{array}{l}1.4497 \\
(1.09)\end{array}$ & $\begin{array}{l}1.5320 \\
(1.02)\end{array}$ & $\begin{array}{l}2.2501 \\
(1.10)\end{array}$ \\
\hline & $\begin{array}{l}1.0973 \\
(0.97)\end{array}$ & $\begin{array}{l}1.2092 \\
(1.03)\end{array}$ & $\begin{array}{l}1.3163 \\
(1.04) \\
A=10\end{array}$ & $\begin{array}{l}1.4377 \\
(1.08)\end{array}$ & $\begin{array}{l}1.5307 \\
(1.02)\end{array}$ & $\begin{array}{l}2.2432 \\
(1.10)\end{array}$ \\
\hline & $\begin{array}{l}1.0961 \\
(0.97)\end{array}$ & $\begin{array}{l}1.2065 \\
(1.03)\end{array}$ & $\begin{array}{l}1.3116 \\
(1.04)\end{array}$ & $\begin{array}{l}1.4260 \\
(1.08)\end{array}$ & $\begin{array}{l}1.5270 \\
(1.02)\end{array}$ & $\begin{array}{l}2.2225 \\
(1.09)\end{array}$ \\
\hline \multicolumn{7}{|c|}{$A=20$} \\
\hline & $(0.98)$ & $(1.02)$ & $(1.02)$ & $(1.03)$ & (1.01) & $(1.02)$ \\
\hline
\end{tabular}

Panel B) Japan

\begin{tabular}{|c|c|c|c|c|c|c|}
\hline$\widetilde{T}=$ & 1 & 2 & 3 & 4 & 5 & 10 \\
\hline \multicolumn{7}{|c|}{$A=2$} \\
\hline & $\begin{array}{l}1.1043 \\
(1.08)\end{array}$ & $\begin{array}{l}1.1949 \\
(1.10)\end{array}$ & $\begin{array}{l}1.3425 \\
(1.24)\end{array}$ & $\begin{array}{l}1.4922 \\
(1.39)\end{array}$ & $\begin{array}{l}1.6266 \\
(1.41)\end{array}$ & $\begin{array}{l}2.3038 \\
(1.43)\end{array}$ \\
\hline \multicolumn{7}{|c|}{$A=5$} \\
\hline & $\begin{array}{l}1.0844 \\
(1.05)\end{array}$ & $\begin{array}{l}1.1639 \\
(1.06)\end{array}$ & $\begin{array}{l}1.2742 \\
(1.14)\end{array}$ & $\begin{array}{l}1.3860 \\
(1.22)\end{array}$ & $\begin{array}{l}1.4808 \\
(1.22)\end{array}$ & $\begin{array}{l}2.0919 \\
(1.19)\end{array}$ \\
\hline \multicolumn{7}{|c|}{$A=10$} \\
\hline & $\begin{array}{l}1.0762 \\
(1.03)\end{array}$ & $\begin{array}{l}1.1551 \\
(1.03)\end{array}$ & $\begin{array}{l}1.2481 \\
(1.07)\end{array}$ & $\begin{array}{l}1.3514 \\
(1.11)\end{array}$ & $\begin{array}{l}1.4470 \\
(1.10)\end{array}$ & $\begin{array}{l}2.0503 \\
(1.09)\end{array}$ \\
\hline \multicolumn{7}{|c|}{$A=20$} \\
\hline & $\begin{array}{l}1.0735 \\
(1.01)\end{array}$ & $\begin{array}{l}1.1513 \\
(1.01)\end{array}$ & $\begin{array}{l}1.2380 \\
(1.03)\end{array}$ & $\begin{array}{l}1.3341 \\
(1.05)\end{array}$ & $\begin{array}{l}1.4288 \\
(1.05)\end{array}$ & $\begin{array}{l}2.0200 \\
(1.05)\end{array}$ \\
\hline
\end{tabular}

(continued ...) 
Panel C) UK

\begin{tabular}{|c|c|c|c|c|c|c|}
\hline$\widetilde{T}=$ & 1 & 2 & 3 & 4 & 5 & 10 \\
\hline \multicolumn{7}{|c|}{$A=2$} \\
\hline & 1.1241 & 1.0773 & 1.2109 & 1.4343 & 1.6020 & 2.6014 \\
\hline & $(1.00)$ & $(1.00)$ & $(1.00)$ & (1.00) & $(1.00)$ & $(1.00)$ \\
\hline \multicolumn{7}{|c|}{$A=5$} \\
\hline & 1.1241 & 1.0773 & 1.2109 & 1.4343 & 1.6020 & 2.6014 \\
\hline & $(1.01)$ & $(0.94)$ & $(0.96)$ & (1.01) & (1.03) & (1.13) \\
\hline \multicolumn{7}{|c|}{$A=10$} \\
\hline & 1.1179 & 1.1004 & 1.2271 & 1.4301 & 1.5896 & 2.5465 \\
\hline & (1.01) & $(0.95)$ & $(0.97)$ & (1.01) & (1.03) & $(1.10)$ \\
\hline \multicolumn{7}{|c|}{$A=20$} \\
\hline & 1.1089 & 1.1529 & 1.2657 & 1.4187 & 1.5554 & 2.3775 \\
\hline & (1.00) & $(0.98)$ & $(0.99)$ & (1.00) & (1.01) & (1.06) \\
\hline
\end{tabular}

Notes: These figures refer to the end-of-period (equal to $1, \ldots, 5,10$ years) economic value, as measured by wealth levels and wealth ratios for the case of an investor acting on the basis of the static buy-and-hold strategy. Initial wealth is assumed to be equal to unity. $\widetilde{T}$ is the investment horizon in years. $A$ is the coefficient of risk aversion in the CRRA utility function defined by equation (6). For each of $A=2,5,10,20$, the first row reports the end-of-period wealth calculated using the definition given by equation (5). Values in parentheses in the second row are ratios of the end-of-period wealth levels obtained in the case of predictability to the end-of-period wealth levels obtained under a random walk exchange rate. 
Table 3. The economic value of predictability: an augmented fundamentals model

Panel A) Canada

\begin{tabular}{lllllll}
\hline \hline$\widetilde{T}=$ & 1 & 2 & 3 & 4 & 5 & 10 \\
\hline \multicolumn{7}{c}{$A=2$} \\
& 1.1034 & 1.2092 & 1.3075 & 1.4219 & 1.5316 & 2.2501 \\
$(0.97)$ & $(1.03)$ & $(1.04)$ & $(1.07)$ & $(1.02)$ & $(1.10)$ \\
& \multicolumn{5}{c}{$A=20$} \\
& 1.1008 & 1.2024 & 1.3030 & 1.4094 & 1.5237 & 2.1901 \\
& $(0.98)$ & $(1.01)$ & $(1.02)$ & $(1.04)$ & $(1.01)$ & $(1.07)$ \\
\hline
\end{tabular}

Panel B) Japan

\begin{tabular}{lllllll}
\hline \hline$\widetilde{T}=$ & 1 & 2 & 3 & 4 & 5 & 10 \\
\hline \multicolumn{5}{c}{$A=2$} \\
& 1.1224 & 1.1930 & 1.3047 & 1.3959 & 1.4782 & 1.9973 \\
$(1.09)$ & $(1.10)$ & $(1.20)$ & $(1.30)$ & $(1.28)$ & $(1.23)$ \\
& \multicolumn{5}{c}{$A=20$} \\
1.0762 & 1.1519 & 1.2365 & 1.3242 & 1.4184 & 1.9897 \\
$(1.01)$ & $(1.01)$ & $(1.03)$ & $(1.04)$ & $(1.04)$ & $(1.02)$ \\
\hline
\end{tabular}

Panel C) UK

\begin{tabular}{lllllll}
\hline \hline$\widetilde{T}=$ & 1 & 2 & 3 & 4 & 5 & 10 \\
\hline \multicolumn{5}{c}{$A=2$} \\
& 1.1241 & 1.0773 & 1.2109 & 1.4343 & 1.6020 & 2.6014 \\
$(1.00)$ & $(1.00)$ & $(1.00)$ & $(1.00)$ & $(1.00)$ & $(1.30)$ \\
& \multicolumn{5}{c}{$A=20$} \\
1.1097 & 1.1510 & 1.2639 & 1.4186 & 1.5546 & 2.2994 \\
$(1.00)$ & $(0.97)$ & $(0.98)$ & $(1.00)$ & $(1.01)$ & $(1.15)$ \\
\hline
\end{tabular}

Notes: These figures refer to the end-of-period (equal to $1, \ldots, 5,10$ years) economic value, as measured by wealth levels and wealth ratios for the case of an investor acting on the basis of the static buy-and-hold strategy. Initial wealth is assumed to be equal to unity. $\widetilde{T}$ is the investment horizon in years. $A$ is the coefficient of risk aversion in the CRRA utility function defined by equation (6). For each of $A=2,20$, the first row reports the end-of-period wealth calculated using the definition given by equation (5). Values in parentheses in the second row are ratios of the end-of-period wealth levels obtained in the case of predictability to the end-of-period wealth levels obtained under a random walk exchange rate. 
Figure's caption

Figure 1 Optimal asset allocation: US/Japan 
Figure 1. Optimal asset allocation: US/Japan
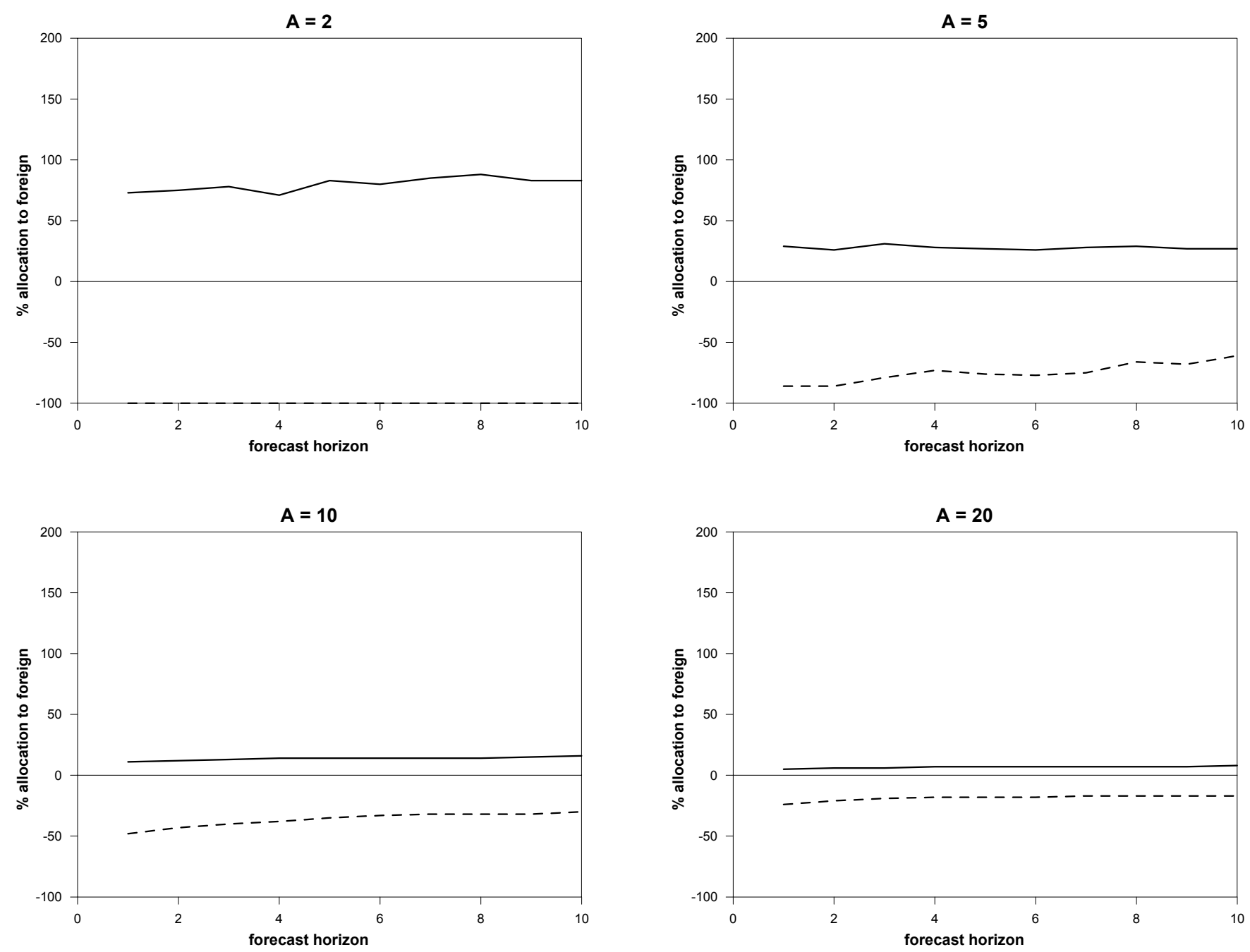